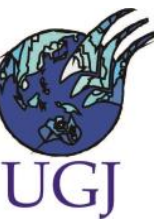

\title{
Kualitas Air Tanah Untuk Kebutuhan Air Minum di Desa Ujung Lero Kecamatan Suppa Kabupaten Pinrang
}

\author{
Nurqamri Putri Basofi ${ }^{1}$, Syukri Nyompa ${ }^{2}$, Amal Arfan ${ }^{3}$ \\ ${ }^{123}$ Universitas Negeri Makassar, Jurusan Geografi \\ Program Studi Pendidikan Geografi \\ Email : uttigeo15@gmail.com
}

(Received: Maret 2019; Reviewed: Maret 2019; Accepted: April 2019; Published: 01 Mei 2019)

Ini adalah artikel dengan akses terbuka dibawah license CC BY-NC-4.0 (C2019 oleh

penulis (https://creativecommons.org/licenses/by-nc/4.0/)

\begin{abstract}
This study aims to: Know the quality of ground water, whether ground water is suitable to use as a source of drinking water and how to determine groundwater quality using the Storet Method. This type of research was a quantitative descriptive research. The population in this study was shallow ground water or dug wells used by the community as a source of drinking water. The sample of this research took based on land use which point I was in a settlement, point II was in a field, point III was in a shrub and point IV was in a pond. The data of this research were analyzed by using the Storet Method. The results showed that the water quality exceeded the maximum level that allowed for drinking water so that the water cannot be used for drinking water needs, the parameter that exceeds the maximum level was at point IV that had salty taste, the color parameter at point III was 20.0 with the maximum limit 15, the turbidity parameter at point IV was 5.480 with a maximum limit of 5 , the TDS parameter at points I - IV is 692, 1178, 6403 and 799 with a maximum limit of 500, the iron parameter at points I and IV were 0.31 and 0.43 with a maximum limit of 0.3 and also a detergent parameter at point IV of 0.110 with a maximum limit of 0.05 and E.Coli parameters at points I, II and IV of 680, 2200 and 200 with a maximum limit of 0 amount of $100 / \mathrm{ml}$. Based on the results measurement and analysis of well water samples, it can be concluded that well water was not suitable to use as drinking water because the water had been polluted. Using the storet method showed that the level of well water pollution can be classified as class D (Severely Polluted) category with poor water conditions for drinking water quality.
\end{abstract}

Keywords: Groundwater Quality; Drinking Water Needs; Ujung Lero.

\section{ABSTRAK}

Penelitian ini bertujuan untuk: Mengetahui kualitas air tanah, Apakah air tanah di layak digunakan sebagai sumber air minum dan cara menentukan kualitas air tanah dengan menggunakan Metode Storet. Jenis penelitian ini merupakan jenis penelitian deskriptif kuantitatif. Populasi dalam penelitian adalah air tanah dangkal atau sumur gali yang digunakan masyarakat sebagai sumber air minum. Adapun Sampel adalah berdasarkan penggunaan lahan yaitu lokasi I merupakan pemukiman, lokasi II ladang, lokasi III semak belukar dan lokasi IV tambak. 
Analisis data yang digunakan pada penelitian ini adalah Metode Storet. Hasil penelitian menunjukkan bahwa kualitas air yaitu melebihi kadar maksimum yang diperbolehkan untuk air minum sehingga air tersebut tidak dapat digunakan untuk air minum, parameter yang melebihi kadar maksimum yaitu parameter rasa pada titik IV yaitu rasanya asin, Parameter warna pada titik III yaitu 20,0 dengan batas maksimum 15, parameter kekeruhan pada titik IV yaitu 5,480 dengan batas maksimum 5, parameter TDS pada titik I - IV yaitu 692, 1178, 6403 dan 799dengan batas maksimum 500, parameter besi pada titik I dan IV yaitu 0,31 dan 0,43 dengan batas maksimum 0,3 dan juga parameter deterjen pada titik IV yaitu 0,110 dengan batas maksimum 0,05 dan parameter E.Coli pada titik I, II dan IV yaitu 680, 2200 dan 200 dengan batas maksimum 0 jumlah 100/ml .Berdasarkan hasil pengukuran dan hasil analisis sampel air sumur diketahui bahwa air sumur tidak layak digunakan sebagai air minum kerna air tersebut sudah tercemar. Dengan menggunakan Metode storet menunjukkan bahwa tingkat pencemaran air sumur tergolong kategori kelas D (Tercemar Berat) dengan kondisi air yang buruk untuk kualitas air minum.

Kata Kunci: Kualitas Air Tanah; Kebutuhan Air Minum; Desa Ujung Lero.

\section{PENDAHULUAN}

Terbatasnya ketersediaan air baku menjadi salah satu masalah yang dihadapi dalam penyediaan layanan air bersih di Indonesia, belum meratanya pelayanan penyediaan air bersih terutama di daerah pedesaan, dan sumber air bersih yang ada belum dimanfaatkan secara maksimal. Bahkan di beberapa wilayah, sumber air bersih yang dimanfaatkan oleh PDAM telah tercemari oleh limbah industri dan limbah domestik, sehingga beban dalam pengolahan air bersih menjadi meningkat. Air bersih adalah air yang dipergunakan untuk keperluan sehari-hari dan kualitasnya memenuhi persyaratan kesehatan air bersih sesuai dengan peraturan perundang-undangan yang berlaku. Kualitas air yang baik meliputi uji kualitas secara fisika, kimia dan biologi, sehingga apabila dikonsumsi tidak menimbulkan efek samping untuk kesehatan (Wulan, 2016).

Kabupaten Pinrang merupakan wilayah provinsi Sulawesi selatan yang secara geografis terletak pada koordinat antara $40^{\circ} 10^{\prime} 30^{\prime \prime}$ sampai $30^{\circ} 19^{\prime} 13^{\prime \prime}$ Lintang Selatan dan 119 $26^{\prime} 30^{\prime \prime}$ sampai $119^{\circ} 47^{\prime} 20^{\prime \prime}$ Bujur Timur.Romang Polong merupakan salah satu kelurahan di Kecamatan Somba Opu dengan luas wilayah 2,71 km2. Kabupaten pinrang terdiri dari 12 kecamatan, 39 kelurahan dan 65 Desa yang meliputi 96 lingkungan dan 181
Dusun ( sebagian besar dari wilayah kecamatan merupakan daerah pesisir yang memiliki luas $1.457,19 \mathrm{~km}$ atau $74,27 \%$ dari luas keseluruhan wilayah kabupaten pinrang dengan panjang garis pantai $\pm 101 \mathrm{~km}$. ( Sumber : kabupaten pinrang dalam angka, 2010)

Desa Ujung Lero merupakan salah satu daerah yang ada di Kecamatan Suppa kabupaten pinrang, yang luasnya $\pm 47 \mathrm{Ha}$. Adapun jarak dari ibu kota kecamatan $17 \mathrm{~km}$ sedangkan jarak dari ibu kota kabupaten yaitu $37 \mathrm{~km}$. dan jarak dari ibu kota provinsi 215 $\mathrm{km}$. mempunyai ketinggian tanah dari permukaan laut 3 meter. Dengan panjang pantai $\pm 2 \mathrm{~km}$. Salah satu desa yang ada di Kecamatan Suppa ini merupakan Lokasi Penelitian.

Permasalahan yang ada di Desa Ujung Lero salah satunya adalah tentang ketersediaan air untuk kebutuhan hidup sebagai sumber air bersih khususnya untuk sumber air minum yang dibutuhkan bagi warga yang tinggal dikawasan tersebut . Adapun Jumlah penduduk Desa Lero pada bulan Desember tahun 2009 adalah 7.321 jiwa. Sedangkan air yang digunakan untuk keperluan rumah tangga dan kehidupan sehari-hari juga semakin meningkat. Oleh karna itu untuk mengurangi biaya konsumsi air minum maka warga di Desa Ujung Lero masih banyak yang memilih menggunakan sumur gali kerna mudah di dapatkan dan 
lebih terjangkau sebagai sumber air minum ataupun keperluan lain untuk rumah tangga.

Di antara sumur gali yang digunakan masyarakat yang ada di daerah tersebut terdapat air minum yang rasanya pahit apabila diminum sehingga masyarakat memilih untuk membuat lagi sumur gali, jadi ada beberapa warga membuat dua sumur gali untuk satu rumah tangga kerna alasan air yang dikonsumsi untuk air minum dan keperluan masak dibedakan dengan sumur gali yang airnya pahit sedangkan sumur tersebut lebih di gunakan untuk keperluan lain. masyarakat yang telah membuat sumur gali yang digunakan untuk sumber air minum seharihari belum diketahui kualitas airnya secara pasti.

Permasalahan-permasalahan yang terjadi tersebut, maka penulis mengadakan penelitian tentang "Kualitas Air Tanah Untuk Kebutuhan Air Minum Di Desa Ujung Lero Kecamatan Suppa Kabupaten Pinrang”.

\section{METODE}

Sasaran penelitian adalah wilayah penelitian yang menjadi objek penelitian. Penelitian ini dilaksanakan di Desa Ujung Lero Kecamatan Suppa Kabupaten Pinrang untuk mengetahui kualitas air tanahnya, penelitian di lakukan pada sumur-sumur yang ada di Desa Ujung Lero Kecamatan Suppa Kabupaten Pinrang dengan teknik purposive sampling. Metode purposive sampling merupakan cara menentukan titik sampel penelitian secara sengaja. Sampel penelitian diuji dengan pertimbangan tertentu. Penelitian ini menggambarkan tingkat kualitas air tanah dilokasi penelitian yang saat ini masih digunakan oleh masyarakat Desa Ujung Lero untuk memenuhi kebutuhannya sehari-hari. Adapun variable-variabel yang digunakan untuk analisis kualitas air tanah yaitu parameter fisika (suhu, bau, rasa, kekeruhan, warna), Parameter kimia (pH,TDS, Kesadahan, Besi (Fe), Nitrat, Nitrit), deterjen dan Parameter Biologi (EColi).

Dalam menyelesaikan suatu penelitian diperlukan suatu desain penelitian agar peneltian dapat berjalan lancar. Adapun tahap desain penelitian dimulai dari proses persiapan sampai pada tahap penyusunan hasil:

1. Pra Penelitian

Tahap ini merupakan tahap persiapan yang meliputi penyusunan proposal penelitian, pengambilan data maupun peta dasar, seminar proposal serta pengurusan surat izin penelitian.

2. Penelitian

a. Tahap persiapan

Tahap ini mulai dilakukan dengan penyelesaian izin melaksanakan penelitian, penyiapan alat-alat penunjang yang akan digunakan dilapangan untuk memberikan kelancaran penelitian. Selanjutnya, alat-alat yang digunakan diperiksa terlebih dahulu kondisinya untuk memastikan alat siap untuk digunakan penelitian.

b. Alat dan bahan

Adapun alat dan bahan yang akan digunakan dalam penelitian yaitu: 1) GPS untuk menentukan titik koordinat tempat pengambilan sampel, 2)Botol sampel untuk tempat penyimpanan sampel, 3) Thermometer untuk mengukur suhu, 4) $\mathrm{pH}$ meter untuk pengukuran $\mathrm{pH}$ air, 5)Air Suling atau aquades untuk membersihkan botol sampel, 6)Grab Smapel untuk pengambilan sampel air dari sumur, 7)Lakban hitam utntuk menutupi botol biasa, 8)Meteran untuk mengukur kedalaman sumur, 9) Alat tulis menulis untuk mencatat hasil pengukuran di lokasi penelitian, dan 10)Kamera untuk dokumentasi penelitian

c. Pengambilan Sampel

Pengambilan sampel di lapangan yaitu dengan menggunakan metode purposif sampling. Sampel yang akan di ambil dilapangan adalah air sumur gali yang telah ditentukan lokasinya. Cara pengambilan sampel air sumur menggunakan Water Sampler Van Dorn yang terlebih dahulu harus dicuci dengan air sumur sampel. Sampel air sumur diambil pada pagi hari. Jika 
pengambilan sampel dilakukan pada beberapa titik maka volume sampel 1 dari setiap titik harus sama. Botol yang digunakan untuk sampel air adalah botol plastik biasa yang telah ditutupi lakban hitam agar terhindar dari sinar matahari yang terlebih dahulu dicuci dengan menggunakan air sumur sampel. Hal ini memastikan agar botol sampel terhindar dari zat-zat yang bias tercampur dengan sampel air. Pengambilan sampel di fokuskan berdasarkan pada penggunaan lahan daerah penelitian.

d. Analisis sampel

Untuk analisis sampel parameter fisika, kimia dan biologi dilakukan dengan pengujian secara langsung dilapangan dan analisis sampel yang dilaboratorium kualitas air. Data yang digunakan adalah data primer (hasil pengujian parameter fisik, kimia dan biologi) maupun data sekunder (Peta Lokasi Penelitian, Sebaran sumur gali, Penggunaan Lahan, Jenis Tanah, Geologi, Sebaran Kondisi Air, Kulitas Air Tanah Di Desa Ujung Lero Kecamatan Suppa Kabupaten Pinrang.

Teknik analisis data yang digunakan adalah analisis data secara deskriptif kuantitatif yaitu menjawab masalah penelitian sehingga analisis data dalam penelitian diuraikan berdasarkan masalah yang dimaksud. Data yang didapat dilapangan dan hasil uji laboratorium dibandingkan dengan standar kualitas air minum menurut MenKes RI No. 492/MENKES/PER/IV/2010 untuk mengetahui kualitas air tanah untuk kebutuhan air minum di Desa Ujung Lero Kecamatan Suppa Kabupaten Pinrang. Peraturan tersebut telah disesuaikan dengan standar yang ditetapkan WHO dan dianalisis menggunakan metode STORET untuk mengetahui kondisi dan tingkat ketercemaran air dilokasi penelitian.

Penggunaan metode STORET dilakukan dengan langkah-langkah sebagai berikut :

1. Pengumpulan data kualitas dan debit air secara periodik ( time series).

2. Bandingkan data hasil pengukuran kualitas air dengan nilai baku mutu sesuai dengan kelas air.

3. Jika hasil pengukuran memenuhi nilai baku mutu air maka diberi skor 0 .

4. Jika hasil pengukuran tidak memenuhi nilai baku mutu air, maka diberi skor pada tabel

5. Jumlah Negatif dari seluruh parameter dihitung dan ditentukan status mutunya dari jumlah skor yang didapat dengan menggunakan sistem nilai.

6. Jika dalam perhitungan, tidak ditemukan nilai ambang batas suatu parameter yang diukur, maka parameter tersebut tidak perlu dihitung.

Tabel 1. Nilai dan Skor Metode Storet

\begin{tabular}{|c|c|c|c|c|}
\hline \multirow{2}{*}{ Jumlah } & \multirow{2}{*}{ Nilai } & \multicolumn{3}{|c|}{ Parameter } \\
\hline & & Fisika & Kimia & Biologi \\
\hline \multirow{3}{*}{$<10$} & Maksimum & -1 & -2 & -3 \\
\hline & Minimum & -1 & -2 & -3 \\
\hline & Rata - rata & -3 & -6 & -9 \\
\hline \multirow{3}{*}{$>10$} & Maksimum & -2 & -4 & -6 \\
\hline & Minimum & -2 & -4 & -6 \\
\hline & Rata-rata & -6 & -2 & -18 \\
\hline
\end{tabular}

Sumber: Hasil Pengolahan Data, 2018 


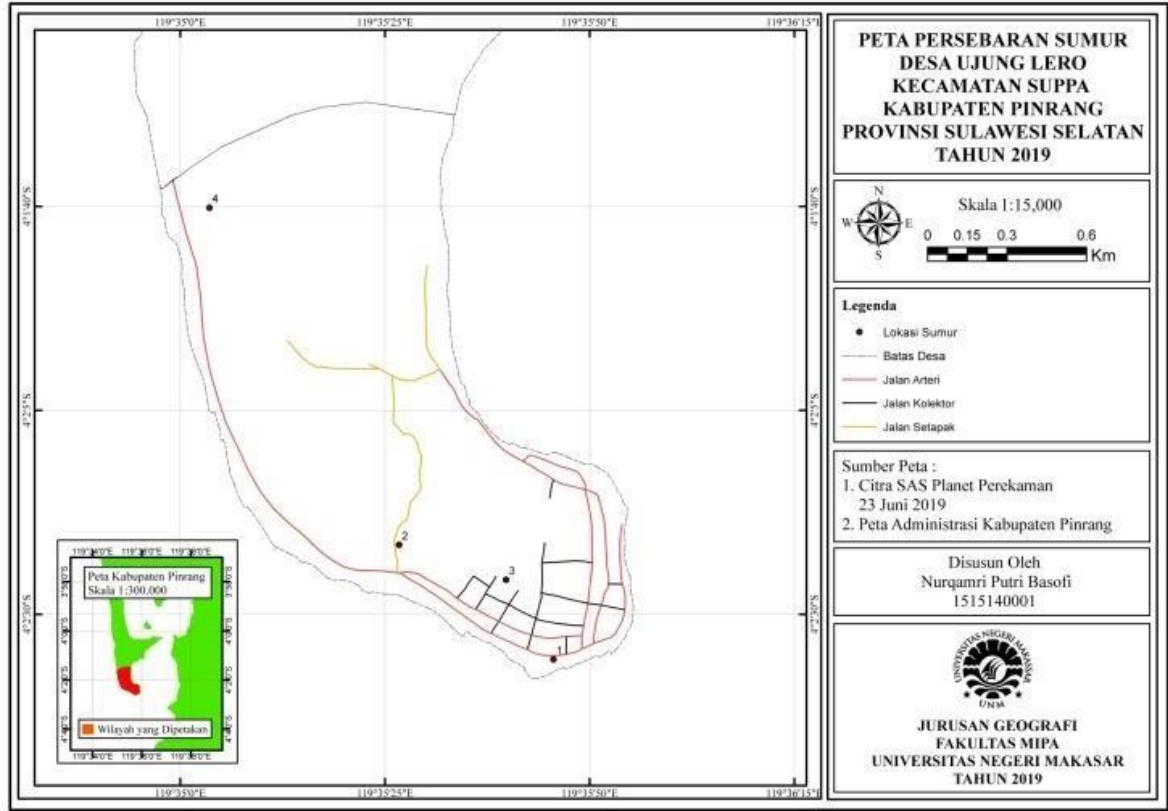

Gambar 1. Peta Persebaran Sumur

Cara untuk menentukan status mutu air adalah dengan menggunakan sistem nilai dari US- EPA dengan mengklasifikasikan mutu air denga empat kelas , yaitu :
1. Kelas A
: Baik Sekali, skor
$=0$ (memenuhi baku mutu)
2. Kelas B
: Baik, skor
$=-1 \mathrm{~s} / \mathrm{d}-10$ (cemar ringan)
3. Kelas C
: Sedang, skor
$=-11 \mathrm{~s} / \mathrm{d}-30$ (cemar sedang)
4. Kelas D
: Buruk, skor
$=\geq-31$ (cemar berat)

\section{HASIL DAN PEMBAHASAN}

\section{Hasil}

Tabel 2. Hasil Analisis Parameter fisika di Desa Ujung Lero Kecamatan Suppa Kabupaten Pinrang

\begin{tabular}{|c|c|c|c|c|c|c|}
\hline \multirow{2}{*}{ No } & \multirow{2}{*}{$\begin{array}{c}\text { Paramet } \\
\text { er }\end{array}$} & \multicolumn{4}{|c|}{ Kode Sampel } & \multirow{2}{*}{$\begin{array}{c}\text { Kriteria Kualitas Air } \\
\text { Minum Yang Di } \\
\text { Perbolehkan }\end{array}$} \\
\hline & & $\mathbf{I}$ & II & III & IV & \\
\hline 1 & Rasa & - & - & - & Asin & Tidak Berasa \\
\hline 2 & $\mathrm{Bau}$ & - & - & - & - & Tidak Berbau \\
\hline 3 & Warna & 5,0 & 10,0 & 20,0 & 10,0 & 15 \\
\hline 4 & Suhu & 27 & 27 & 28 & 29 & $<30$ \\
\hline 5 & $\begin{array}{c}\text { Kekeruha } \\
n\end{array}$ & 0,218 & 0,888 & 2,990 & 5,480 & 5 \\
\hline 6 & TDS & $\begin{array}{c}692,0 \\
\text { Sumb }\end{array}$ & $\begin{array}{l}1178,0 \\
\text { : Hasil F }\end{array}$ & $\begin{array}{l}6403,0 \\
\text { ngolaha }\end{array}$ & $\begin{array}{c}799,0 \\
\text { Data, } 2\end{array}$ & 500 \\
\hline
\end{tabular}


Tabel 3. Hasil Analisis Parameter kimia di Desa Ujung Lero Kecamatan Suppa Kabupaten Pinrang

\begin{tabular}{|c|c|c|c|c|c|c|}
\hline \multirow{2}{*}{ No } & \multirow{2}{*}{ Parameter } & \multicolumn{4}{|c|}{ Kode Sampel } & \multirow{2}{*}{$\begin{array}{c}\text { Kriteria Kualitas Air } \\
\text { Minum Yang Di } \\
\text { Perbolehkan }\end{array}$} \\
\hline & & $\mathbf{I}$ & II & III & IV & \\
\hline 1 & $\mathrm{pH}$ & 7 & 8 & 7 & 9 & $6,5-8,5$ \\
\hline 2 & Besi & 0,31 & $* t \mathrm{tt}$ & 0,43 & $-0,58$ & 0,3 \\
\hline 3 & Kesadahan & 41,642 & $* \mathrm{tt}$ & $* \mathrm{tt}$ & $* \mathrm{tt}$ & 500 \\
\hline 4 & Nitrat & 0,085 & 0,411 & 3,546 & $-0,048$ & 50 \\
\hline 5 & Nitrit & 0,47 & 0,062 & 0,018 & $-0,005$ & 3 \\
\hline 6 & Deterjen & $* \mathrm{tt}$ & $* t \mathrm{tt}$ & 0,040 & 0,110 & 0,05 \\
\hline
\end{tabular}

Sumber: Hasil Pengolahan Data, 2018

Tabel 4. Hasil Analisis Parameter Biologi di Desa Ujung Lero Kecamatan Suppa Kabupaten Pinrang

\begin{tabular}{cccccccc}
\hline & & \multicolumn{3}{c}{ Kode Sampel } & & Kriteria Kualitas Air \\
\cline { 3 - 6 } No & Parameter & I & II & III & IV & Minum Yang Di \\
& & & & & & & Perbolehkan \\
\hline 1. & E.coli & & 680 & 2200 & $*$ tt & 200 & 0 \\
\hline
\end{tabular}

Sumber: Hasil Pengolahan Data, 2018

Tabel 5. Hasil Perhitungan Menggunakan Metode Storet

\begin{tabular}{ccccccc}
\hline Parameter & Satuan & Titik 1 & Titik 2 & Titik 3 & Titik 4 & $\begin{array}{c}\text { Kadar } \\
\text { Maksimum }\end{array}$ \\
\hline Bau & - & - & - & - & - & - \\
Rasa & - & - & - & - & - & - \\
Suhu & ${ }^{\circ} \mathrm{C}$ & 0 & 0 & 0 & 0 & 30 \\
Warna & Skala TCU & 0 & 0 & -5 & 0 & 15 \\
Kekeruhan & Skala NTU & 0 & 0 & 0 & -5 & 5 \\
pH & - & 0 & 0 & 0 & -10 & $6,5-8,5$ \\
Kesadahan & $m g / 1$ & 0 & 0 & 0 & 0 & 500 \\
TDS & $\mathrm{mg} / 1$ & -10 & -10 & -10 & -10 & 500
\end{tabular}




\begin{tabular}{|c|c|c|c|c|c|c|}
\hline Besi & $\mathrm{mg} / \mathrm{l}$ & -10 & 0 & -20 & 0 & 0,3 \\
\hline Nitrat & $\mathrm{mg} / \mathrm{l}$ & 0 & 0 & 0 & 0 & 50 \\
\hline Nitrit & $\mathrm{mg} / \mathrm{l}$ & 0 & 0 & 0 & 0 & 3 \\
\hline Deterjen & Jumlah/100 ml & 0 & - & 0 & -20 & 0,05 \\
\hline E-Coli & & -30 & -30 & 0 & -30 & 0 \\
\hline \multicolumn{2}{|c|}{ Total } & -50 & -40 & -35 & -75 & \\
\hline
\end{tabular}

Sumber: Hasil Pengolahan Data, 2018

Tabel 6. Status Mutu Air adalah dengan menggunakan Sistem Nilai Dari US-EPA

\begin{tabular}{cccc}
\hline Titik & Total skor & Klasifikasi kelas & Status mutu air \\
\hline 1 & -50 & $\mathrm{D}$ & Tercemar Berat \\
2 & -40 & $\mathrm{D}$ & Tercemar Berat \\
3 & -35 & $\mathrm{D}$ & Tercemar Berat \\
4 & -75 & $\mathrm{D}$ & Tercemar Berat \\
\hline
\end{tabular}

Sumber: Hasil Pengolahan Data, 2018

\section{Pembahasan}

Pada lokasi I daerah pemukiman memiliki tingkat parameter TDS yang tinggi yaitu 692,0 (batas kriteria 500), tingkat parameter Besi yaitu 0,31 (batas kriteria 0,3) dan E.coli -30 (batas kriteria 0) yang melebihi kadar maksimum yang diperbolehkan untuk air minum menurut Peraturan Menteri Kesehatan No. 492 tahun 2010. Dari hasil analisis menggunakan Metode Storet pada lokasi I memiliki skor -50 yang berarti masuk dalam kategori kelas D (Tercemar Berat) sehingga tidak dapat digunakan untuk sebagai air minum. Lokasi I yang merupakan pemukiman, parameter rasa, bau, warna, suhu, $\mathrm{pH}$, kesadahan, nitrat, nitrit, dan deterjen berada di bawah ambang batas maksimum yang diperbolehkan untuk air minum menurut Peraturan Menteri Kesehatan No. 492 tahun 2010.

Pada lokasi II pemukiman di sekitar ladang memiliki tingkat parameter TDS yang tinggi yaitu 1178,0 (batas kriteria 500) dan E.coli -30 (batas kriteria 0) yang melebihi kadar maksimum yang diperbolehkan untuk air minum menurut Peraturan Menteri Kesehatan No. 492 tahun 2010. Dari hasil analisis menggunakan Metode Storet pada lokasi II memiliki skor

-40 yang berarti masuk dalam kategori kelas D (Tercemar Berat) sehingga tidak dapat digunakan untuk sebagai air minum. Lokasi II yang merupakan daerah pemukiman disekitar ladang, parameter rasa, bau, warna, suhu, $\mathrm{pH}$, kesadahan, besi, nitrat, nitrit, dan deterjen berada di bawah ambang batas maksimum yang diperbolehkan untuk air minum menurut Peraturan Menteri Kesehatan No. 492 tahun 2010.

Pada lokasi III pemukiman di sekitar semak belukar memiliki tingkat parameter warna yaitu 20,0 (batas kriteria 15), TDS yaitu 6403,0 (batas kriteria 500), dan besi yaitu 0,43 (batas kriteria 0,3) yang melebihi kadar maksimum yang diperbolehkan untuk air minum menurut Peraturan Menteri Kesehatan No. 492 tahun 2010. Dari hasil analisis menggunakan Metode Storet pada lokasi III memiliki skor -35 yang berarti masuk dalam kategori kelas D (Tercemar Berat) sehingga tidak dapat digunakan untuk sebagai air minum. Lokasi III yang merupakan daerah pemukiman disekitar semak belukar, parameter rasa, bau, suhu, $\mathrm{pH}$, kesadahan, nitrat, nitrit, deterjen dan E.Coli berada di bawah ambang batas maksimum yang diperbolehkan untuk air minum menurut Peraturan Menteri Kesehatan No. 492 tahun 2010.

Pada lokasi IV pemukiman di sekitar tambak memiliki tingkat parameter rasa yaitu asin (batas kriteria yaitu tidak berbau), kekeruhan yaitu 5,480 (batas kriteria 5),TDS yaitu 799,0 (batas kriteria 500), pH yaitu 9 (batas kriteria 
6,5-8,5), Deterjen yaitu 0,110 (batas kriteria 0,05 ) dan E.coli -30 (batas kriteria 0) yang melebihi kadar maksimum yang diperbolehkan.

Untuk air minum menurut Peraturan Menteri Kesehatan No. 492 tahun 2010. Dari hasil analisis menggunakan Metode Storet pada lokasi III memiliki skor -75 yang berarti masuk dalam kategori kelas D (Tercemar Berat) sehingga tidak dapat digunakan untuk sebagai air minum. Lokasi IV yang merupakan daerah pemukiman disekitar tambak, parameter bau, warna, suhu, kesadahan, besi, nitrat, dan nitrit berada di bawah ambang batas maksimum yang diperbolehkan untuk air minum menurut Peraturan Menteri Kesehatan No. 492 tahun 2010.

Berdasarkan analisis sampel menunjukkan bahwa semua sampel pada titik I - IV melebihi batas maksimum yang diperbolehkan untuk air minum menurut Peraturan Menteri Kesehatan No. 492 tahun 2010 kerna kadar maksimum yang diperbolehkan untuk TDS Yaitu 500 NTU, dengan nilai pada titik I yaitu 692,0 , pada titik II yaitu 1178,0 , pada titik III yaitu 6403,0 dan pada titik IV yaitu 799,0. Tingginya nilai TDS pada setiap titik disebabkan karena material yang tersuspensi sangat banyak.

Efek dari nilai TDS ataupun kesadahan terhadap kesehatan tergantung pada spesies kimia penyebab masalah tersebut (Juli soemirat Slamet, 2002). Penyebab umum terjadinya TDS adalah bahan anorganik berupa ion-ion yang umum dijumpai di perairan. Sebagai contoh air buangan sering mengandung molekul sabun, deterjen yang larut misalnya air buangan rumah tangga.

Peraturan Menteri kesehatan Republik Indonesia Nomor 492/MENKES/PER/IV/2010 memberikan batas maksimum untuk coliform total adalah 0 . Hasil analisis kandungan bakteri coliform total pada sampel air sumur gali di wilayah penelitian menunjukkan bahwa pada titik III tidak terdeteksi sedangkan pada titik I, II, dan IV nilainya yaitu 680, 2200, dan 200 sehingga melebihi batas maksimum yang diperbolehkan untuk air minum. Mengindikasikan bahwa air tersebut telah tercemar oleh kotoran manusia atau hewan yang dapat menyebabkan penyakit penyakit saluran pencernaan. Semua sampel berada di atas ambang baku mutu air yang diperbolehkan untuk air yang peruntukannya sebagai air minum yaitu tidak boleh ada bakteri air.

\section{SIMPULAN DAN SARAN}

\section{Kesimpulan}

Berdasarkan hasil analisis data di lapangan dan hasil uji laboratorium, maka dapat disimpulkan bahwa : Kualitas air tanah yang ada di Desa Ujung Lero Kecamatan Suppa Kabupaten Pinrang yaitu melebihi kadar maksimum yang diperbolehkan untuk air minum sehingga air tersebut tidak dapat digunakan untuk air minum. Berdasarkan hasil pengukuran dan hasil analisis sampel air sumur diketahui bahwa air tersebut tidak layak digunakan sebagai air minum karena air tersebut sudah tercemar. Dengan menggunakan Metode storet menunjukkan bahwa tingkat pencemaran air tergolong kategori kelas D (Tercemar Berat) dengan kondisi air yang buruk untuk kualitas air minum.

\section{Saran}

Adapun Saran untuk penelitian selanjutnya, sebaiknya titik sampel airnya lebih bervariasi dan lebih luas dan menambah variabel penelitian dengan menggunakan metode lain sehingga didapatkan hasil yang saling melengkapi antara satu dengan yang lainnya.

\section{DAFTAR RUJUKAN}

Keputusan Menteri Kesehatan Republik Indonesia No. 907/Menkes/Sk/Vii/2002 Syarat- Syarat Dan Pengawasan Air Minum

Peraturan Menteri Kesehatan Republik Indonesia Nomor 492/MENKES/PER/IV/2010 Tentang Persyaratan Kualitas Air Minum.

Peraturan Pemerintah Republik Indonesia Nomor 82 Tahun 2001. Tentan Pengelolaan Kualitas Air Dan Pengendalian Pencemaran Air

Slamet, Juli Soemirat, 2002, Kesehatan Lingkungan, Yogyakarta: Gajah Mada University Press 
Soemirat, 2009. Kesehatan Lingkungan,

Yogyakarta: Gajah Mada University

Press

Wulan, 2016, Analisis Kualitas Air Sumur

Masyarakat Kelurahan Lalolara

Kecamatan Kambu, Skripsi, Kendari :

Universitas Halu Oleo

Editor In Chief

Rosmini Maru

rosminimaru@unm.ac.id

Publisher

Geography Education, Postgraduate

Program, Universitas Negeri Makassar

$\mathrm{Jl}$. Bonto Langkasa Gunungsari Baru

Makassar, 90222 Kampus PPs UNM

Makassar Gedung AB ruang 01, Indonesia

Email : ugj@unm.ac.id

Info Berlangganan Jurnal

085299874629 / Ihsan 